\title{
Microsurgical Extraction of a Malfunctioned Pipeline Embolization Device Following Complete Deployment
}

\author{
Dale Ding, Kenneth C. Liu \\ Department of Neurological Surgery, University of Virginia, Charlottesville, VA, United States of America
}

\begin{abstract}
The Pipeline Embolization Device (PED) is an effective treatment approach for complex intracranial aneurysms. Intraprocedural complications during PED deployment are seldom reported. We report a rare complication of a PED malfunction identified immediately following complete deployment during endovascular treatment of a giant middle cerebral artery (MCA) bifurcation aneurysm. After multiple failed attempts at endovascular retrieval of the malfunctioned PED, the patient was taken for microsurgical extraction due to accumulation of thrombus on the proximal unopened portion of the stent and widespread distal dissemination of emboli. After removing the PED from the vessel lumen and resecting the giant aneurysm, we could not reanastamose the proximal MCA to the distal segment. The management of PED malfunction is poorly understood. While removal of an incompletely deployed PED may be undertaken with limited adverse effects, retrieval of a fully deployed PED is associated with a much higher risk of morbidity. Until larger case series of such complications better define the risks and benefits of endovascular or microsurgical retrieval of malfunctioned PEDs, the management of these rare intraprocedural complications will be based on the unique aspects of each individual case and the expertise of the treating neurointerventionalist.
\end{abstract}

Keywords Endovascular procedures, Intracranial aneurysm, Intraoperative complications, Stents, Stroke
J Cerebrovasc Endovasc Neurosurg. 2013 September; 15(3):241-245

Received : 25 June 2013

Revised : 6 August 2013

Accepted : 6 August 2013

Correspondence to Kenneth C. Liu

Department of Neurological Surgery, University of Virginia Health System, Charlottesville, VA 22908, United States of America
Tel : 1-434-924-2735
Fax : 1-434-924-9656
E-mail : kcl3j@hscmail.mcc.virginia.edu

This is an Open Access article distributed under the terms of the Creative Commons Attribution Noncoms Commercial License /http://creativecommons.org/licenses/by-nc/3.0) Which permits unrestricted noncommercial use, distribution, and reproduction in any medium, provided the original work is properly cited.

\section{INTRODUCTION}

Giant intracranial aneurysms are exceedingly difficult to successfully treat by either microsurgical or endovascular approaches. ${ }^{3) 11)}$ The natural history of giant aneurysms is significantly more malignant than that of their smaller counterparts. ${ }^{113)}$ The pipeline embolization device (PED) is a flow-diverting stent developed for treating giant aneurysms via endovascular reconstruction of the parent artery. ${ }^{7)}$ A myriad of single- and multicenter studies have demonstrated the relative safety and efficacy of the PED. ${ }^{2 / 89) 14}$ )
Intraprocedural complications during PED deployment are infrequently reported and complications associated with device malfunction are quite rare. $\left.{ }^{6}\right) \mathrm{We}$ present a case of a completely deployed, malfunctioned PED refractory to endovascular retrieval that generated thromboembolic sequelae and required microsurgical extraction.

\section{CASE REPORT}

A 59 year-old female presented with seizures. Computed tomography angiography (CTA) head dem- 

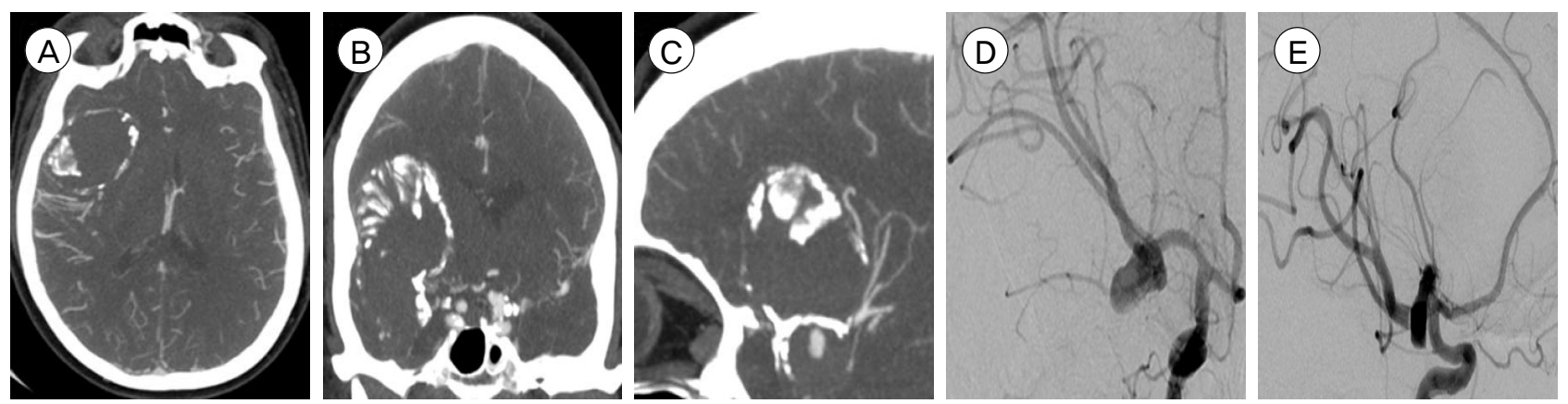

Fig. 1. Computed tomography angiography $(C T A)$ head $(A)$ axial, $(B)$ coronal, and $(C)$ sagittal views demonstrating a giant, partially thrombosed $4.5 \times 3.3 \mathrm{~cm}$ right middle cerebral artery $(\mathrm{MCA})$ bifurcation aneurysm with an atherosclerotic, calcified dome. Digital subtraction angiography (DSA), right internal carotid artery (ICA) injection, (D) antero-posterior (AP) and (E) lateral views again demonstrating the giant MCA bifurcation aneurysm. Most of the aneurysm sac does not fill with contrast due to a significant degree of intrasaccular thrombosis.

onstrated a giant right middle cerebral artery (MCA) aneurysm with mass effect on the adjacent frontal and temporal lobes (Fig. 1). The decision was made to treat the aneurysm with a flow-diverting stent. The patient underwent digital subtraction angiography (DSA), revealing a partially thrombosed, giant right MCA bifurcation aneurysm with a recanalized portion measuring $11.1 \times 7 \times 7 \mathrm{~mm}$. A ReFlex 058 catheter (Reverse Medical, Irvine, CA, USA) was advanced through a 6 French shuttle sheath placed in the right common carotid artery (CCA) into the distal right internal carotid artery (ICA). Under continuous roadmap guidance, a Marksman microcatheter (ev3, Irvine, CA, USA) was advanced over a Transcend microguidewire (Boston
Scientific, Fremont, CA, USA) through the ReFlex catheter into an M3 MCA branch distal to the aneurysm. A $3.25 \times 25 \mathrm{~mm}$ PED was deployed through the Marksman catheter across the neck of the aneurysm.

However, during deployment of the PED, its proximal edge became pinched (Fig. 2). After removal of the ReFlex catheter, attempts to dilate the proximal portion of the stent with a balloon were unsuccessful. After control angiograms through the guide catheter in the CCA demonstrated sluggish flow through the distal right MCA branches, the decision was made to remove the PED. However, since the deployment wire had been removed from the stent, it was no lon-
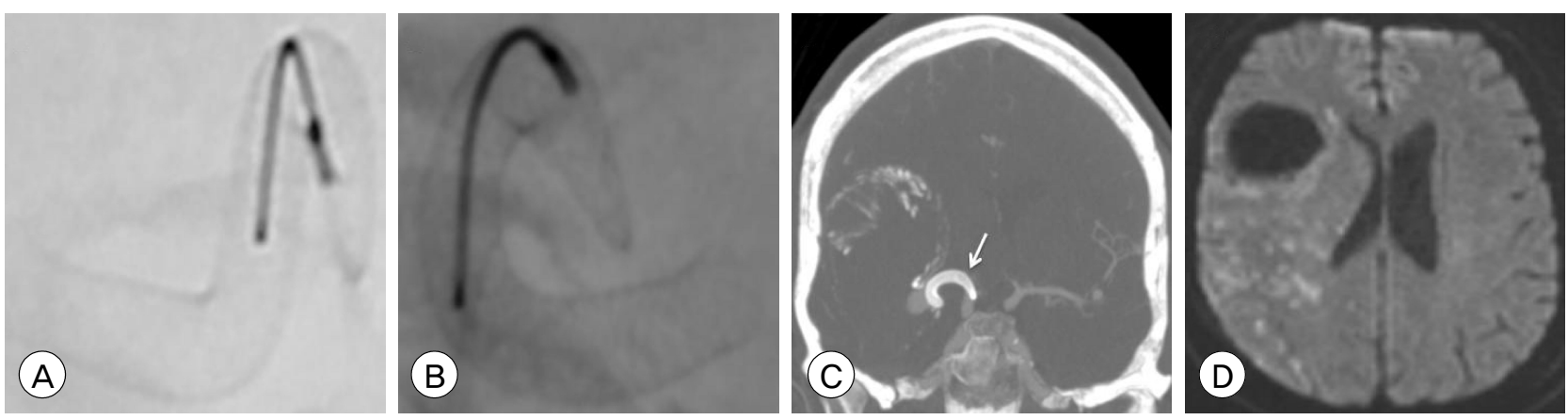

Fig. 2. Initial treatment DSA, (A) AP and (B) lateral views, demonstrating the incompletely deployed PED with a proximally pinched portion and retained transcend microguidewire. The microguidewire was eventually removed but the proximally stenosed portion of the stent could not be dilated and the stent could not be retrieved. (C) CTA head, coronal view, following the initial treatment DSA demonstrating the incompletely deployed PED (arrow) with stenosis of the proximal segment of the stent. (D) Magnetic resonance imaging diffusion weighted imaging, axial view, following the second failed retrieval DSA demonstrating multifocal acute infarcts of the right MCA distribution (DSA: digital subtraction angiography, AP: antero-posterior, PED: pipeline embolization device, CTA: computed tomography angiography, MCA: middle cerebral artery). 
ger possible to retract the proximally pinched stent. The Marksman catheter was removed and a final control angiogram showed less delay in distal MCA flow, no thrombus formation on the stent, and no evidence of distal emboli. The patient was taken to the intensive care unit on therapeutic anticoagulation with a heparin infusion in addition to standard dual antiplatelet therapy (aspirin $325 \mathrm{mg}$ and clopidogrel 75 mg daily). She awoke with a left pronator drift but was otherwise neurologically intact. However, post-procedural CT perfusion continued to show delayed flow through the right MCA.

Therefore the patient was taken back to the neurointerventional suite the next day. Repeat DSA found thrombus formation along the proximal PED with sluggish filling of the distal MCA. An attempted thrombolysis was performed with an infusion of 10 mg of abciximab but was unsuccessful. Next, multiple attempts were made to retrieve the PED utilizing a variety of devices including Goose Neck snares (Microvena, White Bear Lake, MN, USA), an Alligator retrieval device (Chestnut Medical Technologies, Menlo Park, CA, USA), and a Merci Retriever (Concentric Medical, Mountain View, CA, USA) but they all failed. Ultimately the procedure was aborted. The final control angiogram at this point demonstrated a large, flow-limiting thrombus in the M1 trunk and very sluggish flow distally. The patient began to develop a dense left-sided hemiparesis after the failed retrieval attempt and post-procedure magnetic resonance imaging (MRI) demonstrated multiple acute right MCA distribution thromboembolic infarcts (Fig. 2).

Due to the patient's deteriorating neurological exam and the inability to retrieve the partially thrombosed PED by endovascular approaches, neurosurgery was consulted and we emergently decided to take the patient for microsurgical extraction of the PED to restore flow to the MCA. Upon performing a wide right-sided craniotomy, the giant, partially thrombosed MCA aneurysm was immediately evident upon dural opening. The calcified dome was opened and intra-aneurysmal thrombus was debulked. Upon removal of the thrombus, the lumen of the MCA was exposed and the PED was easily removed (Fig. 3). The proximal MCA M1 segment was identified just distal to the ICA bifurcation and proximal vascular control was achieved with a temporary clip. The M2 branches were seen incorporated within the aneurysm neck. The excess aneurysm dome was resected but due to the anatomy of the neck, the opened aneurysm dome could not be reapproximated with a clip. Therefore the remainder of the aneurysm was resected, resulting in detachment of the posterior MCA
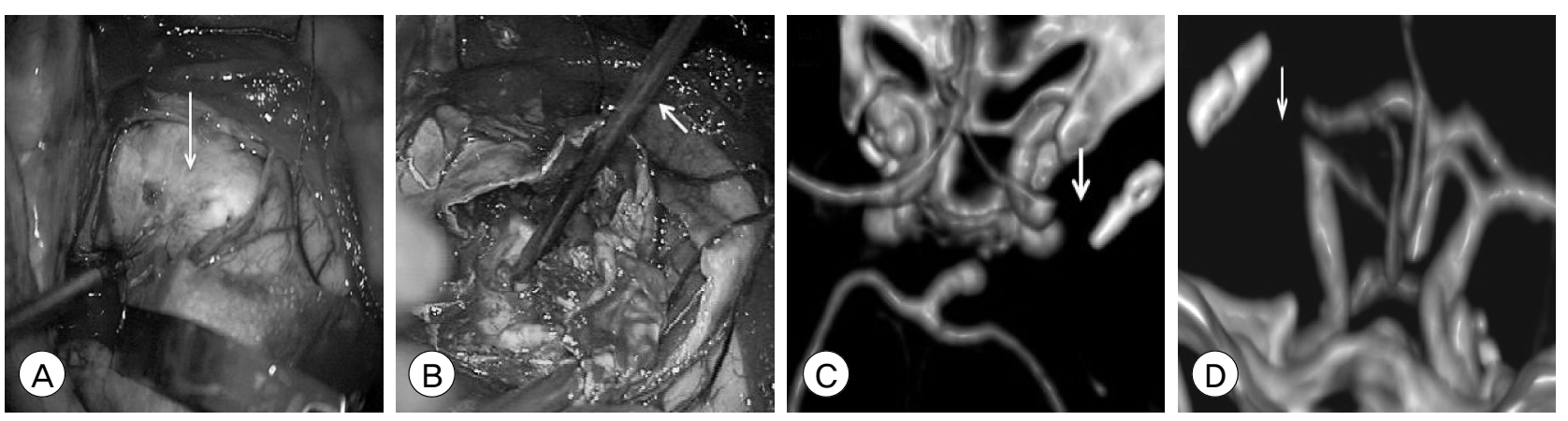

Fig. 3. (A) Intraoperative photograph after dural opening demonstrating the atherosclerotic, calcified dome (arrow) of the giant MCA bifurcation aneurysm. (B) Intraoperative photograph after opening the aneurysm dome and debulking the intrasaccular thrombus demonstrating removal of the incompletely PED (arrow) from the lumen of the MCA M1 segment. Post-operative CTA head 3-dimensional reconstruction, (C) axial and (D) coronal views, demonstrating absence of the right MCA at its origin from the ICA bifurcation (arrow). After aneurysm resection, the detached posterior division of the MCA M2 segment was unable to be reanastamosed to proximal the M1 segment (MCA: middle cerebral artery, PED: pipeline embolization device, CTA: computed tomography angiography, ICA: internal carotid artery). 
M2 division from M1 trunk. The senior author (KCL) attempted to reanastamose the posterior M2 division to the M1 but due to the friable nature of the vessel walls, the 8-0 nylon suture would not hold. Given the length of time that the vessel had been occluded and the likelihood that the infarct had completed, the decision was made to abort the surgery at this time to prevent hyperperfusion injury. The clips were left in place and the bone flap was left off to allow for infarct-related edema. As expected, the patient awoke from surgery with a dense left-sided hemiplegia. The patient underwent percutaneous gastrostomy and was discharged to a rehab facility 1 week post-operatively. The patient subsequently underwent cranioplasty 2 months later with an unchanged neurological exam.

\section{DISCUSSION}

The rate of major morbidity associated with PED treatment of intracranial aneurysms is approximately $5 \%$ and mortality about $1 \%{ }^{6}{ }^{6}$ While PED complications related to the device itself are fortunately very rare, the ensuing sequelae may be catastrophic. Due to the paucity of device-related PED complications, strategies for their management are poorly defined. If PED malfunction is noted prior to complete deployment, an attempt should be made to retract the stent through the deployment catheter. Colby et al. reported removal of 5 PEDs, 2 with failed distal deployment, 1 with failed mid-portion deployment, 1 with distal dislodgement from the parent vessel, and one with distal malposition, utilizing endovascular corking and pseudo-corking techniques. $\left.{ }^{5}\right)$ However, in all of the aforementioned cases, the PED had not been fully deployed with the proximal portion of the device retained within the delivery microcatheter.

In this case, the proximal PED failure was not noted until the stent had been completely released from the delivery catheter thereby significantly increasing the difficulty of endovascular retrieval. The retrieval of a
PED following complete deployment has not been well described in the literature. Therefore the management and ensuing outcomes for these rare circumstances are very poorly defined. Chen et al. reported 2 cases of deformed Enterprise stents (Codman, Miami Lakes, FL, USA) that were removed with an Alligator retrieval device after complete deployment during stent-assisted coil embolization of intracranial aneurysms. ${ }^{4)}$ Oh et al. retrieved a Neuroform stent (Boston Scientific, Fremont, CA, USA) that dislodged during treatment of intracranial atherosclerosis of the supraclinoid ICA. ${ }^{10)}$ Multiple endovascular retrieval devices, including the Alligator and multiple snares, were attempted in our case without success.

Open microsurgical retrieval of intravascular objects is associated with a potentially high rate of morbidity. Raftopoulos et al. described an uncomplicated microsurgical extraction of a coil which unraveled and migrated during endovascular coil embolization of an anterior communicating artery (ACOM) aneurysm. ${ }^{12)}$ Unfortunately in our case, we were unable to reanastamose the distal M1 segment to its proximal segment after opening the MCA to extract the PED (Fig. 3). While the patient had already suffered multiple thromboembolic infarcts in the same vascular distribution, the microsurgical intervention eliminated any chance for future recovery.

\section{CONCLUSION}

As the role of the PED in the treatment of intracranial aneurysms continues to evolve and as its use continues to become more widespread, rare complications such as the one we encountered will become more common. While our case illustrates the first reported instance of microsurgical extraction of a malfunctioned PED, the outcome is clearly suboptimal. With rapid development of new neuroendovascular technology, a simpler solution for retrieval of malfunctioned PEDs may soon emerge. Until such ad- 
vances are available, the management of malfunctioned PEDs after complete endovascular deployment remains determined on a case-specific basis and by the expert opinion of experienced cerebrovascular surgeons and neurointerventionalists.

\section{REFERENCES}

1. Unruptured intracranial aneurysms-risk of rupture and risks of surgical intervention. International Study of Unruptured Intracranial Aneurysms Investigators. N Engl J Med. 1998 Dec 10;339(24):1725-33.

2. Becske T, Kallmes DF, Saatci I, McDougall CG, Szikora I, Lanzino G, et al. Pipeline for Uncoilable or Failed Aneurysms: Results from a Multicenter Clinical Trial. Radiology. 2013 Jun;267(3):858-68.

3. Cantore G, Santoro A, Guidetti G, Delfinis CP, Colonnese C, Passacantilli E. Surgical treatment of giant intracranial aneurysms: Current viewpoint. Neurosurgery. 2008 Oct;63(4 Suppl 2):279-89; discussion 289-90.

4. Chen M, Goldstein-Smith L. Endovascular rescue of a misshapen intracranial stent: Report of two cases. J Neurointerv Surg. 2011 Mar;3(1):25-6.

5. Colby GP, Gomez JF, Lin LM, Paul AR, Coon AL. In situ removal of the pipeline embolization device: The 'corking' and 'pseudo-corking' techniques. J Neurointerv Surg. 2013 Mar;5(2):e6.

6. Fargen KM, Velat GJ, Lawson MF, Mocco J, Hoh BL. Review of reported complications associated with the Pipeline Embolization Device. World Neurosurg. 2012 Mar-Apr;77(3-4):403-4.
7. Fiorella D, Lylyk P, Szikora I, Kelly ME, Albuquerque FC, McDougall CG, et al. Curative cerebrovascular reconstruction with the Pipeline embolization device: The emergence of definitive endovascular therapy for intracranial aneurysms. J Neurointerv Surg. 2009 Jul;1(1):56-65.

8. McAuliffe W, Wycoco V, Rice H, Phatouros C, Singh TJ, Wenderoth J. Immediate and midterm results following treatment of unruptured intracranial aneurysms with the pipeline embolization device. AJNR Am J Neuroradiol. 2012 Jan;33(1):164-70.

9. Nelson PK, Lylyk P, Szikora I, Wetzel SG, Wanke I, Fiorella D. The pipeline embolization device for the intracranial treatment of aneurysms trial. AJNR Am J Neuroradiol. 2011 Jan;32(1):34-40.

10. Oh Y, Hwang DH, Ko YH, Kang IW, Kim IS, Hur CW. Foreign body removal by snare loop: During intracranial stent procedure. Neurointervention. 2012 Feb;7(1):50-3.

11. Parkinson RJ, Eddleman CS, Batjer HH, Bendok BR. Giant intracranial aneurysms: Endovascular challenges. Neurosurgery. 2006 Nov;59(5 Suppl 3):S3-103-12; discussion S3-113.

12. Raftopoulos C, Goffette P, Billa RF, Mathurin P. Transvascular coil hooking procedure to retrieve an unraveled Guglielmi detachable coil: Technical note. Neurosurgery. 2002 Apr;50(4):912-4; discussion 914-5.

13. Wiebers DO, Whisnant JP, Huston J, 3rd, Meissner I, Brown RD, Jr., Piepgras DG, et al. Unruptured intracranial aneurysms: Natural history, clinical outcome, and risks of surgical and endovascular treatment. Lancet. 2003 Jul 12;362(9378):103-10.

14. Yu SC, Kwok CK, Cheng PW, Chan KY, Lau SS, Lui $\mathrm{WM}$, et al. Intracranial aneurysms: Midterm outcome of pipeline embolization device- A prospective study in 143 patients with 178 aneurysms. Radiology. 2012 Dec;265(3): 893-901. 